\title{
Brevibacterium lutescens sp. nov., from human and environmental samples
}

\author{
Georges Wauters, ${ }^{1}$ Véronique Avesani, ${ }^{1}$ Kim Laffineur, ${ }^{1}$ \\ Jacqueline Charlier, ${ }^{1}$ Michèle Janssens, ${ }^{1}$ Bernard Van Bosterhaut ${ }^{2}$ \\ and Michel Delmée ${ }^{1}$ \\ ${ }^{1}$ University of Louvain, Faculty of Medicine, Microbiology Unit, B-1200 Brussels, Belgium \\ ${ }^{2}$ Centre Hospitalier de Mouscron, 7700 Mouscron, Belgium
}

Correspondence

Georges Wauters

wauters@mblg.ucl.ac.be
Recently, a coryneform bacterium belonging to the genus Brevibacterium was reported as a cause of peritonitis in a patient undergoing continuous ambulatory peritoneal dialysis (Wauters et al., 2000b). Its conventional phenotypic characteristics were consistent with those of Brevibacterium otitidis, and 16S rRNA gene sequencing revealed $98.8 \%$ similarity to the sequence of the type strain of that species, which was rather low, but compatible with membership of the same species (Stackebrandt \& Goebel, 1994). Later, three B. otitidis-like strains were collected that exhibited a mean of $98.8 \%$ similarity to B. otitidis in their $16 \mathrm{~S}$ rRNA sequences, two from clinical samples and one from the environment. They were studied more extensively along with the peritonitis strain. A few phenotypic characteristics and DNA-DNA hybridization results clearly indicated that the four strains, including the peritonitis strain, belonged to a novel species, closely related to but distinct from B. otitidis, for which the name Brevibacterium lutescens sp. nov. is proposed.

The four novel strains were of human and environmental origin. Strain $\mathrm{CF} 87^{\mathrm{T}}$ was isolated from peritoneal fluid (Wauters et al., 2000b), strain CF32 from an infected ear discharge, strain CF60 from a peritoneal dialysate fluid and strain CF100 from a peptone preparation. They were stored

Abbreviation: CFA, cellular fatty acid.

The GenBank/EMBL/DDBJ accession number for the 16S rDNA sequence of strain $\mathrm{CF}^{\top} 7^{\top}$ is AJ488509.

$16 \mathrm{~S}$ rDNA sequence similarities between $B$. lutescens sp. nov. CF87 ${ }^{\top}$ and related species are available as supplementary data in IJSEM Online. in glycerol at $-20^{\circ} \mathrm{C}$ and cultured on blood agar at $37^{\circ} \mathrm{C}$ in air for the purposes of this study. The following reference strains were included for phenotypic comparison: Brevibacterium casei ATCC $35513^{\mathrm{T}}$ and DSM 9658, Brevibacterium epidermidis ATCC 49089, DSM 9585 and DSM 9586, Brevibacterium mcbrellneri DSM $9583^{\mathrm{T}}$ and DSM 9584, B. otitidis DSM $10718^{\mathrm{T}}$ and CCUG 37312, Brevibacterium iodinum LMG 2201, Brevibacterium linens LMG 3915 and Brevibacterium paucivorans DSM $13657^{\mathrm{T}}$, DSM 13658, DSM 13659 and DSM 13660. In addition, the following clinical isolates from our collection were included in the study: one B. otitidis strain (CF65), confirmed by $16 \mathrm{~S}$ rRNA gene sequencing and by DNA-DNA hybridization, and eight B. casei and seven B. paucivorans strains, all of them confirmed by $16 \mathrm{~S}$ rRNA gene sequencing.

Most phenotypic characteristics were studied as described previously (Funke et al., 1997; Wauters et al., 1998, 2000a, 2001). Pyrrolidonyl arylamidase, $\alpha$-glucosidase and $N$-acetyl$\beta$-D-glucosaminidase were tested using diagnostic tablets (Rosco). Assimilation/alkalinization of $\gamma$-aminobutyric acid was tested using Simmons' citrate agar, replacing citrate by $0 \cdot 1 \%(\mathrm{w} / \mathrm{v})$ of the substrate. Acid production from phenylacetate was examined as follows: $0.1 \mathrm{ml}$ phenylacetate was thoroughly mixed in $100 \mathrm{ml}$ phosphate buffer $(0.001 \mathrm{M}, \mathrm{pH} 7 \cdot 4)$ and $0.2 \mathrm{ml}$ of a $1 \%(\mathrm{w} / \mathrm{v})$ bromocresol purple solution was added; $0.5 \mathrm{ml}$ of this reagent was mixed with $0.5 \mathrm{ml}$ of a milky suspension (8-9 McFarland) in distilled water obtained from a $24 \mathrm{~h}$ culture on TSA. Tubes were incubated overnight at $37^{\circ} \mathrm{C}$ and a yellow colour indicated acidification. Carbohydrate assimilation was examined on 50CH strips using AUX medium (bioMérieux). 
API ZYM and API CORYNE strips (bioMérieux) were used according to the manufacturer's instructions.

Antibiotic susceptibility was evaluated by MIC determination using E-test strips (PDM) on Mueller-Hinton blood agar incubated at $37^{\circ} \mathrm{C}$ for $24 \mathrm{~h}$. Penicillin, ampicillin, cefotaxime, cephalothin, erythromycin, ciprofloxacin, gentamicin and vancomycin were tested and the results were interpreted according to the criteria established for staphylococci by the NCCLS (2002).

Cellular fatty acids (CFA) were assayed by GLC using a Delsi chromatograph as described previously (Wauters et al., 1996). Amino acid composition of the peptidoglycan was studied by N. Weiss (DSMZ, Braunschweig, Germany) using a TLC method as outlined by Schleifer \& Kandler (1972).

For 16S rDNA sequencing, DNA was prepared with Chelex 100 resin (Bio-Rad) as described by O'Neil et al. (1996). Briefly, bacteria were lysed by boiling for $15 \mathrm{~min}$ in a $5 \%$ Chelex suspension and centrifuged at $13000 \mathrm{~g}$ for $10 \mathrm{~min}$ to pellet cell debris. A total of $3 \mu \mathrm{l}$ of the supernatant containing extracted DNA was used as a template for PCR. The entire 16S rRNA gene (1500 bp) was amplified by PCR using $16 \mathrm{~S}$ rDNA primers 1522R and 27F (Johnson, 1994). The PCR products were separated by electrophoresis on $1 \cdot 2 \%$ agarose gel and visualized by ethidium bromide staining under UV. A $1.5 \mathrm{~kb}$ fragment was excised from the gel and purified by using a QIAquick gel extraction kit (Qiagen) following the manufacturer's instructions. An ABI PRISM Dye Terminator cycle-sequencing ready reaction kit (Applied Biosystems) was used for sequencing of the PCR product. Sequencing and template preparation were performed in accordance with the instructions of the manufacturer. The universal forward and reverse $16 \mathrm{~S}$ rDNA sequencing primers 321, 530, 1100, 1242 and 1392 (numbered relative to the Escherichia coli 16S rDNA numbering; Johnson, 1994) were used in this study. The sequencing product was purified by ethanol/sodium acetate precipitation (Applied Biosystems) and sequenced with an Applied Biosystems 3100 automatic sequencer. Each $16 \mathrm{~S}$ rDNA was compared with those available in GenBank and EMBL using the BLAST program. The alignment was created using the CLUSTAL X algorithm (Thompson et al., 1997). For construction of the phylogenetic tree, operations of the PHYLIP package (version 3.5c.; J. Felsenstein, Department of Genetics, University of Washington, Seattle, WA, USA) were used. Pairwise evolutionary distances were computed from percentage similarities by the correction of Kimura (1980) and the phylogenetic tree was constructed by the neighbourjoining method (Saitou \& Nei, 1987).

DNA-DNA hybridization was carried out by P. Schumann at the DSMZ. DNA was isolated by chromatography on hydroxyapatite (Cashion et al., 1977). DNA-DNA hybridization was performed as described by De Ley et al. (1970) with the modification described by Huß et al. (1983) and Escara \& Hutton (1980), using a Gilford System model 2600 spectrometer equipped with a Gilford model 2527-R thermoprogrammer and plotter. Renaturation rates were computed with the TRANSFER.BAS program (Jahnke, 1982).

On Gram staining, the four strains were coryneform, Grampositive rods, $2-3 \mu \mathrm{m}$ long. There was no rod-coccus cycle. Colonies on blood agar reached 1-2 mm diameter after $48 \mathrm{~h}$ incubation at $37^{\circ} \mathrm{C}$. They were smooth and yellowish. Aerobic growth occurred at 37,30 and $20^{\circ} \mathrm{C}$. There was growth on agar containing up to $10 \% \mathrm{NaCl}$. Carbohydrates were not acidified. Urease, nitrate reduction, indole production, decarboxylation of lysine and ornithine and arginine dihydrolase were negative. Gelatin and casein were hydrolysed but tyrosine and xanthine were not. Methanethiol was produced. Pyrazinamidase and pyrrolidonyl arylamidase were positive. There was utilization and alkalinization of $\gamma$-aminobutyric acid on Simmons' agar base. A buffered phenylacetate solution was acidified. With Rosco diagnostic tablets, $\alpha$-glucosidase was negative but $N$-acetyl- $\beta$-D-glucosaminidase was positive. With the API ZYM system, only lipase (C14), lipase esterase (C8), leucine arylamidase and phosphoamidase were positive in all strains. Acid and alkaline phosphatase were positive in strain CF100 only. Using 50CH strips, no carbohydrates were assimilated. The API Coryne code obtained with strains CF32, CF60 and CF100 was 6102004 and that for strain $\mathrm{CF} 87^{\mathrm{T}}$ was 6002004 . The strains were susceptible to all antibiotics tested except that strain $\mathrm{CF} 87^{\mathrm{T}}$ was resistant to erythromycin and strain CF100 was resistant to penicillin.

The CFAs were of the branched type, with anteiso C15:0 and anteiso C17:0 being the predominant components, accounting for more than $75 \%$ of the total, as generally observed in brevibacteria (Funke et al., 1997). Although the qualitative composition of the CFAs of the study strains was comparable to that of $B$. otitidis, there were significant quantitative differences in some components, as shown in Table 1. The peptidoglycan was of the Al $\gamma$ type, meso-diaminopimelic acid being the diamino acid. This is consistent with the genus Brevibacterium (Funke et al., 1997).

$16 \mathrm{~S}$ rRNA gene sequencing of strain $\mathrm{CF} 87^{\mathrm{T}}$ revealed the highest similarity $(98 \cdot 8 \%)$ to $B$. otitidis (Table A, available

Table 1. CFA composition of strains of $B$. otitidis and $B$. lutescens sp. nov.

Values are mean (range) percentages of total CFA. The B. otitidis strains tested were DSM $10718^{\mathrm{T}}$, CCUG 37312 and CF65.

\begin{tabular}{|lcc|}
\hline Fatty acid & B. otitidis $(\boldsymbol{n}=\mathbf{3})$ & B. lutescens sp. nov. $(\boldsymbol{n}=\mathbf{4})$ \\
\hline iso $15: 0$ & $17 \cdot 3(15 \cdot 4-21 \cdot 2)$ & $3 \cdot 2(1 \cdot 9-5 \cdot 4)$ \\
anteiso $15: 0$ & $26 \cdot 8(24 \cdot 5-29 \cdot 1)$ & $43 \cdot 3(40 \cdot 0-50 \cdot 9)$ \\
iso $16: 0$ & $17 \cdot 5(8 \cdot 1-20 \cdot 6)$ & $4 \cdot 2(2 \cdot 5-7 \cdot 0)$ \\
iso $17: 0$ & $5 \cdot 2(4 \cdot 3-6 \cdot 8)$ & $0 \cdot 5(0-1 \cdot 1)$ \\
anteiso $17: 0$ & $33 \cdot 6(31 \cdot 3-35 \cdot 3)$ & $40 \cdot 0(33 \cdot 6-50 \cdot 2)$ \\
\hline
\end{tabular}


as supplementary material in IJSEM Online). For the three other strains, $16 \mathrm{~S}$ rDNA similarity was $98 \cdot 5-99 \cdot 0 \%$ to the type strain of B. otitidis and $99 \cdot 3-100 \%$ to $\mathrm{CF} 87^{\mathrm{T}}$. In contrast, strain CF65 displayed $99 \cdot 7 \%$ similarity to B. otitidis and only $98 \cdot 4-98 \cdot 8 \%$ similarity to the four study strains.

DNA-DNA hybridization between strain $\mathrm{CF}^{\mathrm{T}}$ and B. otitidis DSM $10718^{\mathrm{T}}$ showed only $59 \cdot 6 \%$ relatedness, whereas strain CF65 showed $84 \cdot 1 \%$ relatedness to B. otitidis DSM $10718^{\mathrm{T}}$, consistent with the assignment of strain CF65 to the species B. otitidis. Furthermore, levels of relatedness of strains CF32, CF60 and CF100 to strain CF $87^{\mathrm{T}}$ were respectively $77 \cdot 8,82 \cdot 1$ and $75 \cdot 6 \%$, suggesting that they belong to a single species. The DNA G $+\mathrm{C}$ content of strain $\mathrm{CF} 87^{\mathrm{T}}$ was $68 \cdot 8 \mathrm{~mol} \%$.

Phenotypic, chemotaxonomic and 16S rRNA gene sequencing are consistent with the assignment of the study strains to the genus Brevibacterium. They are closely related to B. otitidis by $16 \mathrm{~S}$ rRNA gene sequencing and phenotypic characterization. However, DNA-DNA hybridization clearly suggests that they belong to a distinct species. Some cultural and biochemical characteristics distinguish them from B. otitidis. Although colonies of both species displayed a yellow pigment, pigmentation was often visible

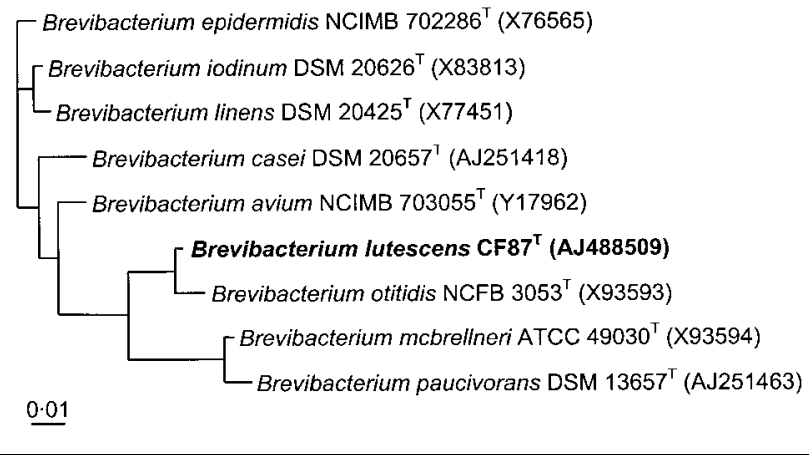

Fig. 1. Unrooted tree based on $16 \mathrm{~S}$ rDNA sequences showing the phylogenetic position of Brevibacterium lutescens sp. nov. CF87 ${ }^{\top}$ within the genus Brevibacterium. Bar, 1 substitution per 100 nt.

sooner in most of the study strains. They grew at a concentration of $10 \% \mathrm{NaCl}$, in contrast to B. otitidis. Using Rosco tablets, $N$-acetyl- $\beta$-D-glucosaminidase (nitrophenyl conjugate) was positive in the study strains and negative in B. otitidis. However, the same enzymic reaction was negative for both species when tested by API CORYNE and API ZYM strips (naphthyl conjugate). Furthermore, the study strains

Table 2. Characteristics that differentiate B. lutescens sp. nov. from other Brevibacterium species

Species: 1, B. lutescens sp. nov. $(n=4) ; 2$, B. otitidis $(n=3) ; 3$, B. casei $(n=10) ; 4$, B. epidermidis $(n=3) ; 5$, B. mcbrellneri $(n=2)$; 6, B. paucivorans $(n=11) ; 7$, B. iodinum $(n=1) ; 8$, B. linens $(n=1)$. + , Positive; - , negative; $(+)$, delayed positive; $+/-$, most strains positive; $-/+$, most strains negative; $\mathrm{W}$, weak reaction; $\mathrm{v}$, variable; ND, not determined.

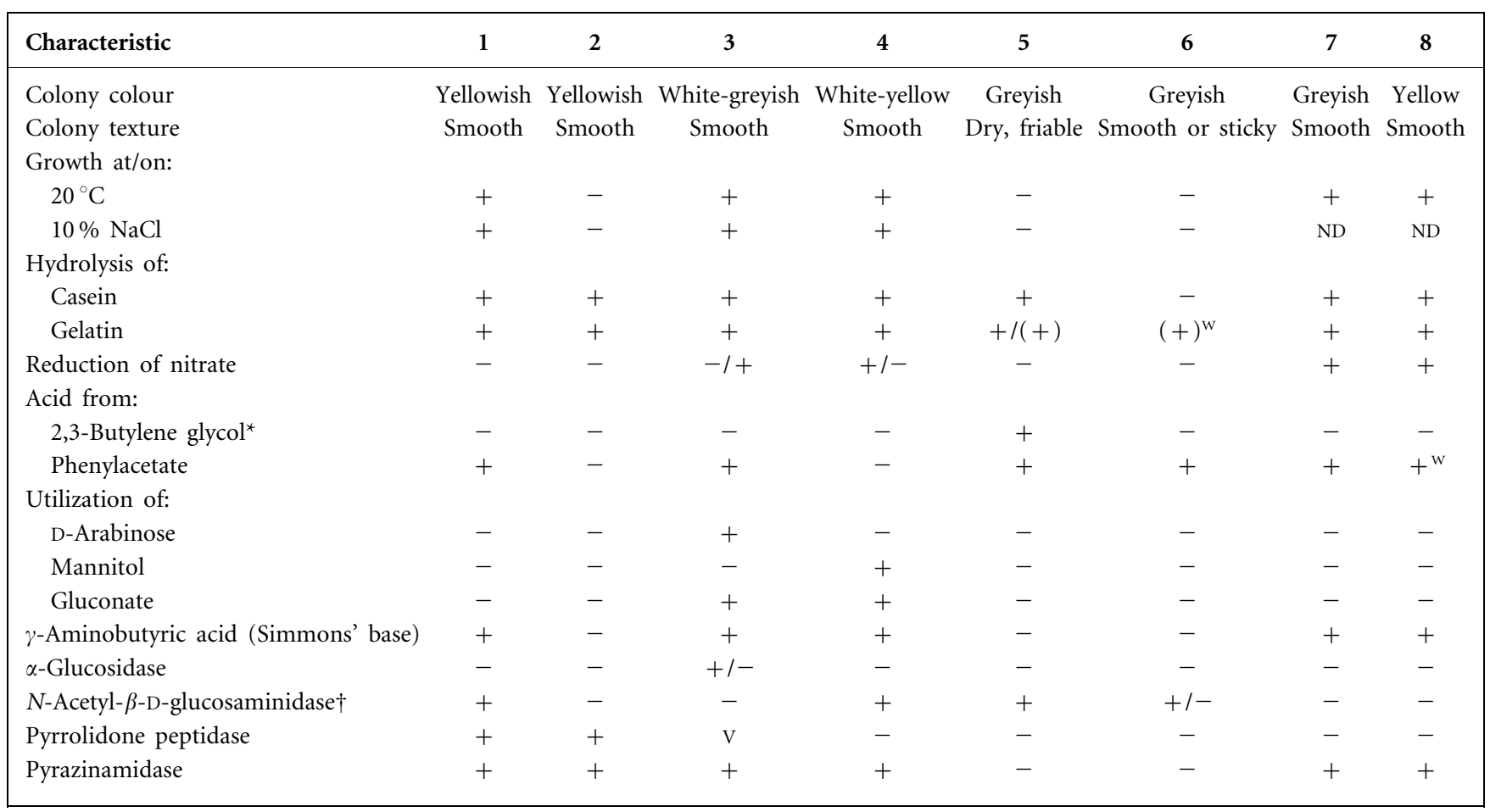

${ }^{\star}$ Determined according to Wauters et al. (2001).

$\dagger$ Tested with nitrophenyl compound. 
grew at $20^{\circ} \mathrm{C}$ within 3 days on blood agar, while B. otitidis strains did not, even after 7 days. Utilization and alkalinization of $\gamma$-aminobutyric acid on Simmons' agar base was positive for the study strains, while the test was negative for $B$. otitidis. The study strains produced acid from phenylacetate using the method described above, while B. otitidis strains did not.

There is genetic, chemotaxonomic and phenotypic evidence that strains $\mathrm{CF} 87^{\mathrm{T}}$, CF32, CF60 and CF100 belong to a single species within the genus Brevibacterium, distinct from the other species described in this genus and most closely related to B. otitidis (Fig. 1). The name Brevibacterium lutescens sp. nov. is proposed for this novel species. Differential characteristics of $B$. lutescens and other brevibacteria are reported in Table 2.

The four strains of $B$. lutescens were isolated from human and environmental sources. Although $\mathrm{CF} 87^{\mathrm{T}}$ was considered clinically relevant as the causative agent of a peritonitis (Wauters et al., 2000b), further observation is needed to assess the potential pathogenicity of this species and to determine its ecological niche.

\section{Description of Brevibacterium lutescens sp. nov.}

Brevibacterium lutescens (lu.tes'cens. L. neut. adj. lutescens yellowish, because colonies exhibit a yellow pigment).

Cells are Gram-positive, non-motile, non-sporulating rods, 2-3 $\mu \mathrm{m}$ long, with diphtheroid arrangement. There is no rod-coccus cycle. Colonies are smooth, yellowish and approximately $1-2 \mathrm{~mm}$ in diameter after $48 \mathrm{~h}$ incubation at $37^{\circ} \mathrm{C}$. Optimal growth occurs between 30 and $37^{\circ} \mathrm{C}$, but strains also grow at $20^{\circ} \mathrm{C}$ within 3 days. Growth occurs in $10 \% \mathrm{NaCl}$. No carbohydrates are acidified or assimilated in the API 50CH system. Urease, pyrazinamidase and nitrate are negative. Methanethiol is produced. Gelatin and casein are hydrolysed but tyrosine, xanthine and aesculin are not. Ethylene glycol is acidified. $\gamma$-Aminobutyric acid is utilized and alkalinized on Simmons' agar base. Phenylacetate is acidified. Pyrrolidonyl peptidase is strongly positive. $N$-Acetyl- $\beta$-D-glucosaminidase is positive when the nitrophenyl compound is used as substrate (Rosco). Using the API ZYM system, lipase (C14), lipase esterase (C8), leucine arylamidase and phosphoamidase are positive. Acid and alkaline phosphatase are variable (negative for the type strain). CFAs are of the branched type, with anteiso 15:0 and anteiso $17: 0$ being the major components. The diamino acid of the peptidoglycan is meso-diaminopimelic acid. The DNA G + C content of the type strain is $68 \cdot 8 \mathrm{~mol} \%$.

The type strain, $\mathrm{CF} 87^{\mathrm{T}}\left(=\mathrm{DSM} 15022^{\mathrm{T}}=\mathrm{CCUG} 46604^{\mathrm{T}}\right)$, was isolated from peritoneal fluid of a patient undergoing dialysis. Three other strains, CF32 ( = DSM 15023 = CCUG 46605), CF60 (=DSM 15024=CCUG 46606) and CF100 ( = DSM 15025 = CCUG 46607), were isolated from human clinical samples and from environmental sources.

\section{References}

Cashion, P., Holder-Franklin, M. A., McCully, J. \& Franklin, M. (1977). A rapid method for the base ratio determination of bacterial DNA. Anal Biochem 81, 461-466.

De Ley, J., Cattoir, H. \& Reynaerts, A. (1970). The quantitative measurement of DNA hybridization from renaturation rates. Eur J Biochem 12, 133-142.

Escara, J. F. \& Hutton, J. R. (1980). Thermal stability and renaturation of DNA in dimethyl sulfoxide solutions: acceleration of the renaturation rate. Biopolymers 19, 1315-1327.

Funke, G., von Graevenitz, A., Clarridge, J. E., III \& Bernard, K. A. (1997). Clinical microbiology of coryneform bacteria. Clin Microbiol Rev 10, 125-159.

Huß, V. A. R., Festl, H. \& Schleifer, K. H. (1983). Studies on the spectrometric determination of DNA hybridization from renaturation rates. Syst Appl Microbiol 4, 184-192.

Jahnke, K.-D. (1992). Basic computer program for evaluation of spectroscopic DNA renaturation data from GILFORD System 2800 spectrometer on a PC/XT/AT type personal computer. J Microbiol Methods 15, 61-73.

Johnson, J. L. (1994). Similarity analysis of rRNAs. In Methods for General and Molecular Bacteriology, pp. 683-700. Edited by P. Gerhardt, R. G. E. Murray, W. A. Wood \& N. R. Krieg. Washington, DC: American Society for Microbiology.

Kimura, M. (1980). A simple method for estimating evolutionary rates of base substitutions through comparative studies of nucleotide sequences. J Mol Evol 16, 111-120.

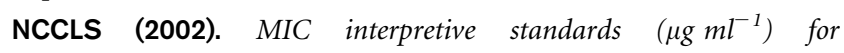
Staphylococcus spp. NCCLS document M100-S12 (M7). Wayne, PA: National Committee for Clinical Laboratory Standards.

O'Neil, G. L., Ogunsola, F. T., Brazier, J. S. \& Duerden, B. I. (1996). Modification of a PCR ribotyping method for application as a routine scheme for Clostridium difficile. Anaerobe 2, 205-209.

Saitou, N. \& Nei, M. (1987). The neighbor-joining method: a new method for reconstructing phylogenetic trees. Mol Biol Evol 4, 406-425.

Schleifer, K. H. \& Kandler, O. (1972). Peptidoglycan types of bacterial cell walls and their taxonomic implications. Bacteriol Rev 36, 407-477.

Stackebrandt, E. \& Goebel, B. M. (1994). Taxonomic note: a place for DNA-DNA reassociation and 16S rRNA sequence analysis in the present species definition in bacteriology. Int J Syst Bacteriol 44, 846-849.

Thompson, J. D., Gibson, T. J., Plewniak, F., Jeanmougin, F. \& Higgins, D. G. (1997). The CLUSTAL_X windows interface: flexible strategies for multiple sequence alignment aided by quality analysis tools. Nucleic Acids Res 25, 4876-4882.

Wauters, G., Driessen, A., Ageron, E., Janssens, M. \& Grimont, P. A. D. (1996). Propionic acid-producing strains previously designated as Corynebacterium xerosis, C. minutissimum, C. striatum, and CDC group $I_{2}$ and group $F_{2}$ coryneforms belong to the species Corynebacterium amycolatum. Int J Syst Bacteriol 46, 653-657.

Wauters, G., Van Bosterhaut, B., Janssens, M. \& Verhaegen, J. (1998). Identification of Corynebacterium amycolatum and other nonlipophilic fermentative corynebacteria of human origin. J Clin Microbiol 36, 1430-1432.

Wauters, G., Charlier, J., Janssens, M. \& Delmée, M. (2000a). Identification of Arthrobacter oxydans, Arthrobacter luteolus sp. nov., and Arthrobacter albus sp. nov., isolated from human clinical specimens. J Clin Microbiol 38, 2412-2415. 
Wauters, G., Van Bosterhaut, B., Avesani, V., Cuvelier, R., Charlier, J., Janssens, M. \& Delmée, M. (2000b). Peritonitis due to Brevibacterium otitidis in a patient undergoing continuous ambulatory peritoneal dialysis. J Clin Microbiol 38, 4292-4293.
Wauters, G., Charlier, J., Janssens, M. \& Delmée, M. (2001). Brevibacterium paucivorans sp. nov., from human clinical specimens. Int $J$ Syst Evol Microbiol 51, 17031707. 